\title{
Efficacy and Safety of Miniscalpel Acupuncture in Knee Degenerative Osteoarthritis Patients: A Study Protocol for a Randomized Controlled Pilot Trial
}

\author{
Seungah Jun ${ }^{1}$, Mu Seob Park ${ }^{1}$, Se Jung Oh ${ }^{1}$, Jung Hee Lee ${ }^{1}$, Han Mi Gong ${ }^{1}$, \\ Seong Hun $\mathrm{Choi}^{2}$, Min Hwangbo ${ }^{3}$, Hyun-Jong Lee ${ }^{1}$, Jae Soo Kim ${ }^{1}$ \\ Departments of ${ }^{1}$ Acupuncture \& Moxibustion Medicine, ${ }^{2}$ Anatomy and Histology, ${ }^{3}$ Oriental Ophthalmology and \\ Otolaryngology and Dermatology, College of Korean Medicine, Daegu Haany University

\section{퇴행성 슬관절염 환자에 대한 도침요법의 효능 및 안전성 연구: 임상예비연구} \\ 전승아 $^{1} \cdot$ 박무섭 $^{1} \cdot$ 오세정 ${ }^{1} \cdot$ 이정희 $^{1} \cdot$ 공한미 $^{1} \cdot$ 최성훈 $^{2} \cdot$ 황보민 $^{3} \cdot$ 이현종 $^{1} \cdot$ 김재수 $^{1}$ \\ 대구한의대학교 한의과대학 ${ }^{1}$ 침구의학교실, ${ }^{2}$ 해부학교실, ${ }^{3}$ 안이비인후피부과학교실
}

\begin{abstract}
Objectives: The Knee degenerative osteoarthritis patients are not satisfied with the conventional therapies of KDOA, which results in the use of alternative therapies. The miniscalpel acupuncture is effective in treating chronic soft tissue, releasing contractures. However, there is little scientific evidence supporting the use of miniscalpel acupuncture in knee degenerative osteoarthritis. This study was designed to obtain basic data for a further large-scale trial as well as provide information about the feasibility of miniscalpel acupuncture in knee degenerative osteoarthritis patients. Methods : We describe the protocol for a randomized controlled pilot clinical trial of 5 weeks duration. Twenty patients will be recruited and randomly allocated to two treatment groups: miniscalpel acupuncture treatment(experimental group); and acupuncture and electro-acupuncture treatment(control group). Miniscalpel acupuncture will be performed once with a 1-week interval for 3 weeks. Electro-acupuncture will be administered twice per week for a period of 3 weeks. The primary outcomes will be measured by visual analogue scale and range of motion. The secondary outcomes will be short-form McGill Pain Questionnaire and Western Ontario and McMaster Universities Osteoarthritis Index. Both primary and secondary outcomes will be measured at baseline and at 1, 2, 3 and 5 weeks(i.e. 2 weeks after treatment completion). Conclusions : This pilot study will provide a basic foundation for a future large-scale trial as well as information about the feasibility of miniscalpel acupuncture in knee degenerative osteoarthritis.
\end{abstract}

Key words : miniscalpel acupuncture, knee degenerative osteoarthritis, pilot study

\section{Introduction}

Knee degenerative osteoarthritis(KDOA) is a widely pre- valent chronic, degenerative disease which often occurs in the elderly. Although knee joint is the one of the largest joint, it is easy to get damaged due to instable anatomical structure.

\footnotetext{
Received May 30, 2016, Revised June 14, 2016, Accepted June 16, 2016

Corresponding author: Jae Soo Kim

Department of Acupuncture \& Moxibustion Medicine, Daegu Oriental Hospital of Daegu Haany University, 136, Sincheondong-ro, Suseong-gu, Daegu 42158, Korea

Tel: +82-53-770-2112, Fax: +82-53-770-2055, E-mail: jaice@daum.net

This study was supported by a grant from the Ministry of Health \& Welfare, Korea(CIMI-15-01-09).

(c) This is an open access article distributed under the terms of the Creative Commons Attribution Non-Commercial License (http://creativecommons.org/licenses/ by-nc/4.0) which permits unrestricted non-commercial use, distribution, and reproduction in any medium, provided the original work is properly cited.
} 
$\mathrm{KDOA}$ is first characterized by degenerative change of the articular cartilage and the subchondral bone of a synovial joint, resulting in physiological impairment.

Conventional therapies for KDOA contain glucosamine, nonsteroidal anti-inflammatory drugs, topical analgesics, intra-articular injection of sodium hyaluronate and surgical treatment ${ }^{1}$. Land-based therapeutic exercise also reduces knee pain, improves physical function of knee and improves quality of life in short terms ${ }^{2}$. Pharmacological therapy and exercises may offer some benefits for patients with knee pain but it is only limited and can cause serious adverse effects ${ }^{3)}$. Current conventional therapies aim to reduce pain, physical disability, preventing structural failure. Surgical therapies are available for people who fail to respond to conservative measures ${ }^{4}$. Most of patients with KDOA are not satisfied with the effects of current pharmacological therapy, which results in the use of alternative therapies ${ }^{5,6}$.

Acupuncture is one of the most famous alternative therapies of KDOA. Efficacy of acupuncture and electroacupuncture(AE) in $\mathrm{KDOA}$ has been evaluated and supported by good evidence ${ }^{7}$. The miniscalpel needle therapy is one of the acupuncture treatment methods. The miniscalpel needling combines traditional Chinese medicine meridian theory and modern surgical principles. Miniscalpel acupuncture(MA) requires comprehension of anatomical structures. Some studies suggest that MA treatment has a better effect and maintenance than regular acupuncture ${ }^{8}$. The MA is effective in treating chronic soft tissue injury such as adhesions, releasing contractures ${ }^{9}$. The MA therapy is known to be more therapeutic than regular acupuncture treatment in chronic musculoskeletal pain ${ }^{10)}$. The aim of MA is to recover the kinetic state of soft tissue from peeling adhesion and remove attached tissues ${ }^{11}$. It has more advantage of quick recovery and pain reduction than regular acupuncture ${ }^{12)}$. However, there is little scientific evidence supporting the use of MA in KDOA. In China, quite a few MA studies are already performed but the studies with good quality and credibility are very rare. Therefore we designed a protocol for an assessor-blinded, randomized controlled pilot trial of $\mathrm{MA}$ in patients with KDOA. The study was designed to obtain basic data for a further large-scale trial and provide information about the feasibility of MA in KDOA patients.

\section{Methods and Design}

\section{Design}

The study is designed to obtain the efficacy and safety of MA in subjects with KDOA. This protocol follows the Declaration of Helsinki and Korean Good Clinical Practice(KGCP). The study will be carried out at Daegu Oriental Hospital of Daegu Haany University, Daegu, Republic of Korea. The trial is registered with the Korean Clinical Research Information Service(CRIS) registry(KCT0001899). Participants will agree to participate in the clinical trial after the researcher provides sufficient information and explanation about this procedure. Written informed consent will be obtained from each participants before any treatment is given.

The obtained assessments will be performed by the independent researcher who is blinded to the assignment of subjects. Although acupuncturists will not be blinded to the group assignments, they will not be involved in the outcome assessments or data analysis. The study design is presented in Fig. 1. The trial will run for five weeks. Subjects will be randomly allocated into two groups. Subjects in a control group will receive acupuncture and electro-acupuncture(AE) for three weeks, and subjects in an experimental group will receive MA for the same period of time. A control group subjects will receive treatment twice a week, whereas an experimental group subjects will receive treatment once a week. Assessments will be performed at baseline and after one, two, three, five weeks.

\section{Participants}

Participants will be recruited through advertisements on hospital websites and on bulletin board. If subjects are interested in participating, they will be invited to the hospital for a screening meeting. Eligibility will be determined by one researcher based on the results of physical and radiography. 


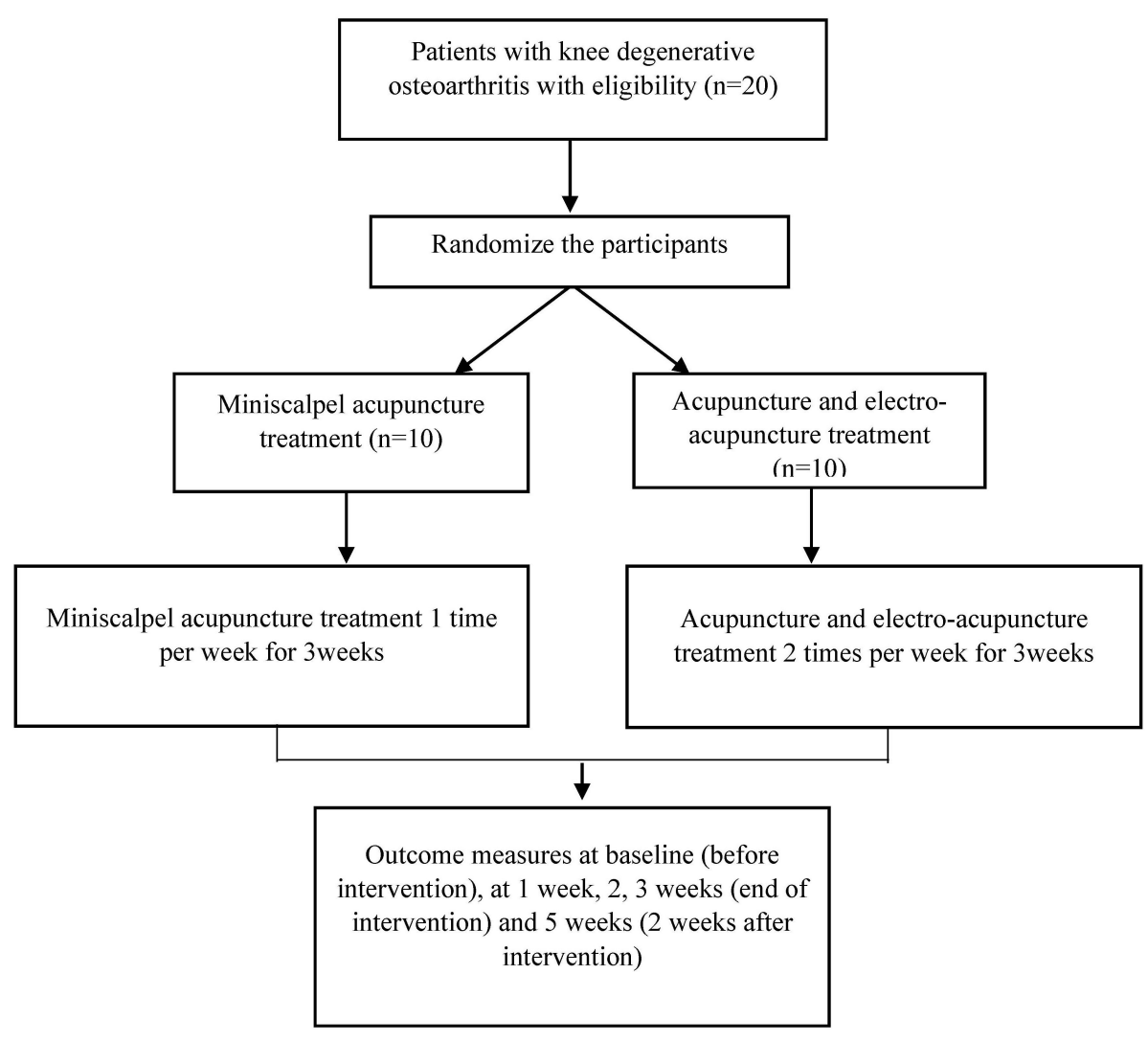

Fig. 1. Flow chart of the pilot randomized controlled trial.
Eligible subjects will be guided through the informed consent process. After consent form is obtained, participants will be randomly allocated to one of the two groups.

\section{Recruitment}

1) Inclusion criteria: Participants must meet the following criteria for inclusion in the study:

(1) Age between 40 and 80 years.

(2) Diagnosed with KDOA according to American College of Rheumatology.

(3) Subjects who had hold medication 1 week ago, if subjects take medication about osteoarthritis.

(4) Kellgren-Lawrence grade 2-4 in knee $\mathrm{x}$-ray.

2) Exclusion criteria: Participants will be excluded from the study if they meet any of the following criteria:

(1) Previous knee surgery for KDOA or other reasons.

(2) Previous intraarticular injection(steroid or Hyaluronic acid) or prolotherapy in the past three months.

(3) Senile dementia, impaired cognitive function, severe psychiatric or psychologic disorders.

(4) Subjects who need steroid or nonsteroidal anti-inflammatory medication to treat other diseases.

(5) Post-traumatic osteoarthritis.

(6) Allergic skin disease, skin ulcer, skin infection.

(7) Pregnancy, lactation, or planned pregnancy.

(8) Diabetics with injection of insulin, cerebral, cardiovascular disease, renal disease.

(9) Use of thrombolytic, antiplatelet, anticoagulant medication.

(10) Abnormal finding on renal or hepatic function blood test.

(11) Insertion of pacemaker.

(12) Deemed ineligible by the recruiting physician.

\section{Randomization}

Written informed consent has been obtained before randomization. Random numbers will be generated by an independent statistics professional through computerized block ran- 
domization using SPSS version 19.0 for Windows(release 14.0K; SPSS Inc. Armonk, NY, USA). Sealed opaque assignment envelopes will be used for allocation concealment. The participants will be randomly assigned to either the experimental group or the control group.

\section{Intervention}

Subjects will be randomly divided into two groups: an experimental group(MA) and a control group(AE). Participants in the experimental group will receive treatment once a week for three weeks whereas participants in the control group will receive treatment twice a week for three weeks. The treatment will be given to only one knee which has more pain. There are no other interventions such as moxibustion, exercises, or lifestyle advice in the study.

1) MA: The following MA points will be used based on previous published work $^{13-15)}$ : quadriceps tendon(EX-LE2), patella ligament(EX-LE210), medial collateral ligament(LR8), lateral collateral ligament(GB33), medial and lateral region of patella, medial and lateral side of quadriceps tendon ${ }^{13)}$. The sterilized disposable MA(DongBang Acupuncture Inc., Korea) $0.5 \mathrm{~mm} \times 50 \mathrm{~mm}$ in size will be used. The western medical doctor will sterilize the insertion site with ethanol 80\%(Firson Inc., Korea) and povidone iodine 10\%(Firson Inc., Korea). The western medical doctor will give an anesthesia while the subjects' knee is flexed about 30 to 45 degree. $27 \mathrm{G} \times 1.5$ inch disposable needle with $1 \%$ lidocaine $3 \mathrm{ml}$ will be used in this procedure. After anesthesia is over the MA will be practiced by Korean medical doctors(KMD) who are licensed by Ministry of Health and Welfare. After all the treatment is over, KMD will check for any abnormality and bleeding.

2) Acupuncture: The following acupuncture points will be used based on the previous work ${ }^{16-18)}$ : unilateral ST34, SP9. SP10, EX-LE4, EX-LE2, LR8, ST36, GB33, EX-LE5. Sterilized disposable acupuncture(Dongbang Acupuncture Inc., Korea) $0.3 \mathrm{~mm} \times 40 \mathrm{~mm}$ will be used by KMD. The needle will be inserted into each of the acupuncture points. After needle insertion, two acupuncture points(unilateral LR8, EX-LE2) will be stimulated by an electro-acupuncture device. The needles will be inserted for $20 \pm 5$ minutes.

\section{Data collection}

The primary outcomes will be measured by visual analogue scale(VAS) and range of motion(ROM). The secondary outcomes will be determined by short form McGill pain questionnaire(SF-MPQ) and Western Ontario and McMaster Universities Osteoarthritis Index(WOMAC). Both outcomes will be assessed at baseline and after one, two, three and five weeks of study. The following treatment and outcome measurement schedules are in Table 1.

\section{1) Primary outcome measurements}

(1) VAS: VAS is a $10-\mathrm{cm}$ measurement instrument to determine the severity of pain. Each subjects will rate pain of knee on a scale of 0 to 10 , where 0 indicates the absence of pain and 10 indicates the worst pain imaginable ${ }^{19,20)}$. In this study, pain of VAS means pain at the point of measurement

(2) ROM: The normal knee ROM will be flexion of 135 degrees and extension of 0 degree. The flexion angle of knee will be more limited if the symptom is severe.

Table 1. Schedule of Treatment and Outcome Measures Throughout the Trial

\begin{tabular}{|c|c|c|c|c|c|c|}
\hline & & \multirow{2}{*}{$\begin{array}{l}\text { Baseline } \\
\text { Week } 0\end{array}$} & \multicolumn{3}{|c|}{ Treatment period } & \multirow{2}{*}{$\begin{array}{c}\text { Follow-up period } \\
\text { Week } 5\end{array}$} \\
\hline & & & Week 1 & Week 2 & Week 3 & \\
\hline \multirow[t]{4}{*}{ Measurement } & VAS & $\vee$ & V & V & $\vee$ & V \\
\hline & ROM & $\vee$ & $\vee$ & $\vee$ & $\vee$ & $\vee$ \\
\hline & SF-MDQ & $\vee$ & $\vee$ & $\vee$ & $\vee$ & $\vee$ \\
\hline & WOMAC & $\vee$ & $\vee$ & $\vee$ & $\vee$ & $\vee$ \\
\hline \multirow[t]{2}{*}{ Treatment } & $M A$ & & $\vee$ & $\vee$ & $\vee$ & \\
\hline & $\mathrm{AE}$ & & $\vee \vee$ & $\vee \vee$ & $\vee \vee$ & \\
\hline
\end{tabular}

VAS : visual analogue scale, ROM : range of motion, SF-MPQ : short-form mcgill pain questionnaire, WOMAC : western ontario and mcmaster universities osteoarthritis index, MA : miniscalpel acupuncture, AE : acupuncture and electro-acupuncture. 


\section{2) Secondary outcome measurements}

(1) SF-MPQ: SF-MPQ is a test for the measurement of sensory, affective and evaluative dimensions ${ }^{21,22}$. The descriptive scale is based on 15 selected words, including 11 items in the sensory domain and 4 items in the emotional domain. Each item is scored from 0 to 3, with 0 indicating no symptoms; 1, mild symptom; 2, moderate symptom; 3, severe symptom. The total score is obtained by summing the individual scores of all 15 items, with higher scores indicating more severe knee pain. PPI measures current pain severity in 6 levels, with scores ranging from 0 to 5; A 0 indicates no pain; 1, mild pain; 2, discomforting pain; 3 , depressing pain; 4, horrible pain; and 5, excruciating pain.

(2) WOMAC: The WOMAC score is a widely used standardized questionnaires to evaluate the condition of patients with osteoarthritis of the knee and hip, including pain, stiffness, and physical functioning of the joints ${ }^{3)}$. The WOMAC consists of 24 items divided into 3 subscales. The index measures five items for pain(score range 0 to 20), two for stiffness(score range 0 to 8), and 17 for physical function(score range 0 to 68$)^{23)}$. Higher scores on the WOMAC indicate worse pain, stiffness, and functional limitations.

\section{Safety}

The safety of this trial will be checked by red blood cell(RBC) count, hemoglobin level, hematocrit, total white blood cell(WBC), differential count, erythrocyte sedimentation rate, platelet, aspartate aminotransferase(AST), alanine aminotransferase(ALT), blood urea nitrogen(BUN), prothrombin time(PT), partial thromboplastin time(PTT), C-reactive protein(CRP) and creatinine level, serum sodium level, serum potassium level, and serum chloride level. All subjects will take blood test twice during this study; at screening and last visit.

To monitor the safety of the MA treatment, we will monitor the occurrence of swelling, redness, itching, peripheral neuritis, hemorrhage, bruising, and pain as the adverse events. The serious adverse effect will be reported to the Institutional Review Board(IRB).

The subjects will be asked to voluntarily report information about adverse effects and the researchers will confirm the occurrence of adverse events through methods such as medical interview. Details about adverse effects such as the date of occurrence, degree of severity, causal relationship with the treatment, other treatments or medications that are suspected to cause the adverse effect, and treatment of the adverse effect will be reported in detail.

\section{Withdrawal and dropout}

All subjects will have the right to withdraw from the study at any time. Participants will be ended at any stage if the subject refuses to continue, withdraws consent, or violates the inclusion or exclusion criteria. The trial will be stopped if the principal investigator believes that there are unacceptable risks of series adverse effects.

\section{Statistical analysis}

The statistical significance level will be set at 5\%. Statistical analysis in this study will be performed using IMB SPSS version 19.0 for Windows(Release 14.0K; IBM SPS Inc., Armonk, NY, USA) and will be based on the Statistics Guidelines for Clinical Trials ${ }^{24}$. The last observation carried forward method will be used for missing data.

The study will identify the comparative equivalence of demographic variables and clinical characteristics between the experimental and control groups by performing the two sample t-test or Mann-Whitney $\mathrm{U}$ test if normality test is satisfied or not for continuous data, chi-square test for categorical data.

A repeated measure two-factor analysis will be performed to identify differences in VAS, ROM, SF-MPQ and WOMAC between the experimental and control group based on time, group and interaction(time difference by group). If the interaction between groups is statistically significant, the point at which the pattern of results between the two groups changes will be checked using the contrast analysis.

All participants who received at least 1 session will undergo an adverse effect evaluation. All adverse effects reported during the clinical trial will be analyzed. To compare groups and the incidence frequency of adverse effects related to MA 
and $\mathrm{AE}$, the chi-square test will be used.

\section{Discussion}

Current management of KDOA takes a comprehensive approach including pharmacological and non-pharmacological interventions. Recently, there have been increased interests in the use of alternative and complementary treatment of $\mathrm{KDOA}$. Alternative medicine is recently receiving more attention for pain control. Acupuncture is the one of the most widely known complementary and alternative medicine. In previous studies, acupuncture is proven to be effective in treating $\mathrm{KDOA}^{25}$. Recently variety of acupuncture treatments such as needle embedding therapy, MA and pharmacopuncture are practiced in Korea. These types of acupuncture have better efficacy than traditional acupuncture ${ }^{26,27}$.

Among many types of acupuncture, MA is used more and more in Korea. From January 1999 to May 2014, twenty eight MA clinical research papers were reported in Korea ${ }^{28)}$. The MA has come to be widely used in treating musculoskeletal diseases $^{29,30)}$. In a review of trends for MA in Korea ${ }^{28)}, 87.1 \%$ of MA studies were about musculoskeletal disease. Among musculoskeletal disease, lumbar spine, neck and shoulder diseases were mostly used. Thirteen studies out of thirty-four studies were about lumbar spine, among which $53.8 \%$ of researches were about herniated intervertebral disc of the lumbar spine. Only $5.8 \%$ of musculoskeletal disease in MA were about knee pain ${ }^{28)}$. Another report ${ }^{13)}$ indicates positive results about MA use in knee pain, but the number of cases is not enough and no control group was used.

There are many MA studies in China but good quality studies are hard to find. One recently published study ${ }^{14)}$ shows a positive result about MA in knee pain but the treatment period is short. Also safety evaluation such as blood test is not included. There is currently lack of research supporting the use of MA in patients with knee pain due to KDOA. Good quality of randomized clinical trial studies is required.

We have therefore designed this pilot trial to guide the design of a full-scale trial. We expect this pilot study to provide clinical evidence for a future large-scale trial as well as information about the feasibility of such a trial.

\section{Acknowledgement}

This study was supported by a grant from the Ministry of Health \& Welfare, Repulic of Korea(CIMI-15-01-09).

\section{Trial status}

This trial is currently in the recruitment phase. Enrollment and trial completion is expected to be finished by the end of August 2016.

\section{Competing interests}

The author declare that they have no competing interests.

\section{Ethics approval}

This protocol has been approved by IRB of Daegu Oriental Hospital of Daegu Haany University, Daegu, Republic of Korea(IRB approval number DHUMC-D-16001).

\section{Date sharing statement}

The data from this trial will be accessible by contacting the corresponding author. The trial findings will be disseminated through open-access journals and national and international conferences. 


\section{References}

1. Manek NJ. Medical management of osteoarthritis. Mayo Clin Proc. $2001 ; 76(5):$ 533-9.

2. Bjordal JM, Ljunggren AE, Klovning A, Slordal L. Non-steroidal anti-inflammatory drugs, including cyclo-oxygenase-2 inhibitors, in osteoarthritic knee pain: Meta-analysis of randomised placebo controlled trials. Bmj. 2004 ; 329(7478) : 1317.

3. McConnell S, Kolopack P, Davis AM. The western ontario and McMaster universities osteoarthritis index(WOMAC): A review of its utility and measurement properties. Arthritis Care \& Research. 2001 ; 45(5) : 453-61.

4. Zhang W, Moskowitz RW, Nuki G, Abramson S, Altman RD, Arden N, et al. OARSI recommendations for the management of hip and knee osteoarthritis, part I: Critical appraisal of existing treatment guidelines and systematic review of current research evidence. Osteoarthritis and Cartilage. 2007 ; 15(9) : 981-1000.

5. McGettigan P, Henry D. Cardiovascular risk and inhibition of cyclooxygenase: A systematic review of the observational studies of selective and nonselective inhibitors of cyclooxygenase 2 . Jama. 2006 ; 296(13) : 1633-44.

6. Blower A, Brooks A, Fenn G, Hill A, Pearce M, Morant S, et al. Emergency admissions for upper gastrointestinal disease and their relation to NSAID use. Aliment Pharmacol Ther. 1997 ; 11(2) : 283-91.

7. Corbett M, Rice S, Madurasinghe V, Slack R, Fayter D, Harden M, et al. Acupuncture and other physical treatments for the relief of pain due to osteoarthritis of the knee: Network meta-analysis. Osteoarthritis and Cartilage. 2013 ; 21(9) : 1290-8.

8. Park S, Kim S, Kim J, Kim S, Lee G. The comparative study of effects between acupotomy and its cotreatment with spine decompression therapy on HIVD patients. The Acupuncture. $2012 ; 29(3): 29-39$.

9. Guo C, Liu N, Li X, Sun H, Hu B, Lu J, et al. Effect of acupotomy on nitric oxide synthase and beta-endorphin in third lumbar vertebrae transverse process syndrome model rats. Journal of Traditional Chinese Medicine. 2014 ; 34(2) : 194-8.

10. Ma C, Wu S, Li G, Xiao X, Mai M, Yan T. Comparison of miniscalpel-needle release, acupuncture needling, and stretching exercise to trigger point in myofascial pain syndrome. Clin J
Pain. 2010 ; 26(3) : 251-7.

11. Lee G, Kim D, Kim H, Yeom S, Kim H, Kim D. The study on the effect of acupotomy in lumbar HIVD. The Journal of Korean Acupuncture \& Moxibustion Medicine Society. 2008 ; 25(4) : 183-90.

12. Kim S. Clinical characteristics of poor responders to acupotomy and safety pretreatment management. The Acupuncture. $2008 ; 25(4): 117-25$.

13. Lee GM, Kim DH, Kim HW, Cho NG, Choi YS, Kim HS, et al. The clinical study on the effect of acupotomy osteoarthritis on knee using "five-finger placed to marking postion". The Acupuncture. 2008; 25(4) : 197-202.

14. Lin M, Li X, Liang W, Liu J, Guo J, Zheng J, et al. Needle-knife therapy improves the clinical symptoms of knee osteoarthritis by inhibiting the expression of inflammatory cytokines. Experimental and Therapeutic Medicine. 2014 ; 7(4) : 835-42.

15. The Acupuncture Compilation Committee. The Acupuncture and Moxibustion(Sang). Seoul. In: :JipMoonDang. 2008 : 441-83.

16. Shin SY, Seo DK, Kim SY, Seo JC, Seo YJ, Lee YJ, et al. The effect of Chinemys reevesii Gray pharmacopuncture for women with knee osteoarthritis . 2015;32(3) : 163-73.

17. Min W, Yeo S, Kim E, Song HS, Koo S, Lee J, et al. Comparison of warm-needling and acupuncture for knee osteoarthritis: A randomized controlled trial. Korean Journal of Acupuncture. 2013 ; 30(1) : 64-72.

18. Jung HC, Jeong SH. A Clinical Study of Knee Joint Osteoarthritis Patients on the Effect of Korean Traditional Medicine Treatment with Acupuncture, Cupping, Physical Therapy and Ganghwalijetong-yeum(Qianghuochutong-yin): Case Series. The Korea Institute of Oriental Medical Diagnostics. 2015 ; 19: 125-32.

19. Revill S, Robinson J, Rosen M, Hogg M. The reliability of a linear analogue for evaluating pain. Anaesthesia. 1976;31(9) : 1191-8.

20. Carlsson AM. Assessment of chronic pain. I. aspects of the reliability and validity of the visual analogue scale. Pain. 1983 ; 16(1): 87-101.

21. Melzack R. The short-form McGill pain questionnaire. Pain. $1987 ; 30(2): 191-7$.

22. Burckhardt CS. The use of the McGill pain questionnaire in assessing arthritis pain. Pain. 1984 ; 19(3) : 305-14.

23. Roos, M Klässbo, LS Lohmander, EM. WOMAC osteoarthritis in- 
dex: Reliability, validity, and responsiveness in patients with arthroscopically assessed osteoarthritis. Scand J Rheumatol. $1999 ; 28(4): 210-5$.

24. Food and Drug Administration. Guidance for industry: E9 statistical principles for clinical trials. Food and Drug Administration: Rockville, Maryland, USA. 1998.

25. Witt C, Brinkhaus B, Jena S, Linde K, Streng A, Wagenpfeil S, et al. Acupuncture in patients with osteoarthritis of the knee: $\mathrm{A}$ randomised trial. The Lancet. 2005 ; 366(9480) : 136-43.

26. Lee SM, Ji YS, Jeon JH, Kim JH, Kim YI. Effect of needle-embedding \& acupuncture therapy on shoulder pain in behcet disease patient: A case report. The Acupuncture. $2013 ; 30(4)$ : 219-24.
27. Park OJ, Kim SG, Lee JJ, Lee SM, Kim SJ, Cho NG. The effect of and bee venom pharmacopuncture in treating lumbar disc herniations. The Acupuncture. 2013 ; 30(5) : 41-50.

28. Yuk DI, Kim KM, Jeon JH, Kim YI, Kim JH. A review of trends for acupotomy. The Acupuncture. $2014 ; 31(3): 35-43$.

29. Yoon S, Lee G, Kang S, Lee E, Han J. Effects of wonli acupuncture procedure in patients with LSS: A clinical, retrospective study. Integrative Medicine Research. 2015 ; 4(1) : 109.

30. Yuk D, Sung I, Song D, Kim M, Hong K. Clinical study of lumbar spine stenosis treated by using acupotomy combined with oriental medical treatments. Journal of Pharmacopuncture. 2013; $16(3): 46$.

\section{국문초록}

목적 : 본 연구는 퇴행성 슬관절염 환자들을 대상으로 도침치료가 통증을 감소시키는데 효과적이고 안전한 치료법임을 증명하기에 적합한지 를 알아보기 위한 예비연구이다. 방법 : 본 연구는 5주간 진행되는 무작위배정 대조군 예비임상연구이며, 총 20명의 피험자들은 시험군(도침 치료)과 대조군(침치료+전침치료)으로 무작위 배정된다. 시험군의 경우에는 주 1 회, 3주간 총 3회의 도침치료를 실시하고 대조군의 경우에 주2회, 3주간 총 6회의 침치료와 전침치료를 받게된다. 1차 유효성 평가변수는 통증에 대한 Visual analogue system와 관절가동범위를, 2차 유효성 평가변수는 Short form McGill pain questionnaire와 Western Ontario and McMaster Universities Osteoarthritis Index로 측정한 다. 평가는 시험시작 전, 시험 1주, 2주, 3주 및 5주후에 이루어지게 된다. 결론 : 본 연구는 추후 본격적인 무작위배정 대조군 임상시험을 위한 예비연구로서, 본 연구를 통해 퇴행성 슬관절염에 있어서 도침치료가 임상적으로 유효함을 증명할 수 있는 근거를 마련해 줄 것이라사료된다. 